\title{
Peer victimization as reported by children, teachers, and parents in relation to children's health symptoms
}

Audhild Løhre ${ }^{1,2^{*}}$, Stian Lydersen ${ }^{3}$, Bård Paulsen ${ }^{4}$, Magne Mæhle ${ }^{5,6}$ and Lars J Vatten ${ }^{1}$

\begin{abstract}
Background: Victims of bullying in school may experience health problems later in life. We have assessed the prevalence of children's health symptoms according to whether peer victimization was reported by the children, by their teachers, or by their parents.
\end{abstract}

Methods: In a cross-sectional study of 419 children in grades 1-10 the frequency of peer victimization was reported by children, teachers and parents. Emotional and somatic symptoms (sadness, anxiety, stomach ache, and headache) were reported by the children.

Frequencies of victimization reported by different informants were compared by the marginal homogeneity test for paired ordinal data, concordance between informants by cross-tables and Spearman's rho, and associations of victimization with health symptoms were estimated by logistic regression.

Results: The concordance of peer victimization reported by children, teachers, and parents varied from complete agreement to complete discordance also for the highest frequency (weekly/daily) of victimization. Children's selfreported frequency of victimization was strongly and positively associated with their reports of emotional and somatic symptoms. Frequency of victimization reported by teachers or parents showed similar but weaker associations with the children's health symptoms.

Conclusion: The agreement between children and significant adults in reporting peer victimization was low to moderate, and the associations of reported victimization with the children's self-reported health symptoms varied substantially between informants. It may be useful to assess prospectively the effects of employing different sources of information related to peer victimization.

\section{Background}

Health consequences of peer victimization include higher prevalence of physical complaints and psychosocial maladjustment [1-13], with fairly similar effects between countries [10]. Williams and co-workers drew attention to the importance of dose, and suggested that higher frequencies of victimization were associated with greater risk of health problems [14]. Persistent victimization over an extended time period also predicts more serious health problems [15].

Bullying usually includes aggressive behaviour with repetitive acts and imbalance of power $[16,17]$. Previous

\footnotetext{
* Correspondence: audhild.lohre@ntnu.no

'Department of Public Health, Faculty of Medicine, Norwegian University of

Science and Technology, Trondheim, Norway

Full list of author information is available at the end of the article
}

research has shown great variation in bullying and peer victimization among children, and differences in results may partly be due to different research methods [18]. Selfreports of victimization and health outcomes are more common than the use of information from teachers, parents or peers [6], but it has been suggested that using several informants may be useful in assessing effects of victimization [19]. Agreement between different informants about children's health and behavioral problems is typically low to moderate [20-23], but little is known about the concordance between children and significant adults in the assessment of victimization caused by bullying. Also, it is not clear how victimization, as reported by different responders, may be associated with health outcomes.

We therefore tested the consistency of victimization reported by the children, teachers, and parents in a 
cross-sectional study of school children. Further, we assessed the association of victimization reported by the three sources with the prevalence of emotional and somatic symptoms (anxiety, sadness, stomach ache, headache), as reported by the children.

\section{Methods}

\section{Participants and procedure}

This study is based on a cross-sectional convenience sample of five schools in Møre and Romsdal County, Norway. The headmasters agreed to participate in two surveys that were set two years apart. Since there is no formal agency for ethical approval of school surveys in Norway, the study was approved by the statutory School Collaborative Committees. In the present analysis, data were used from the first survey that was carried out from May to June 2002.

Parents were informed about the survey in the context of a school meeting, and in each class, teachers informed the children about the survey. Information letters signed by the headmaster and by the principal investigator (AL) were sent to all parents, describing the aims of the survey, and emphasising that participation was voluntary and that the collected information was confidential. Children/parents who did not want to participate were asked to notify their main teacher or headmaster. None of the subjects declined to take part in the survey.

Three schools had grades from 1 to 7 , and two schools had grades from 1 to 10. All children from four schools and all children in grades 7-10 from the fifth school were included. Thus, 423 children between seven and 16 years of age were invited, together with their parents and teachers. One child moved before the data collection started, and three children were on sick leave during the study period. Thus, 419 (99\%) children participated in the study: we received parent responses for 377 (89\%) children, and teacher responses for 403 (95\%) children.

The questionnaire was developed by the first author $(\mathrm{AL})$, and has demonstrated satisfactory construct, content, and face validity, as described in detail elsewhere [24]. Briefly, reliability of the questionnaire was tested in another material gathered from children in grades 3,6 , and 9. For 179 eligible children, the questionnaire was completed by 154 (86\%) children two times, three weeks apart. The test-retest reliability for the 49 ordinal questions was acceptable with $82 \%$ of the Spearman's rho coefficients ranging between 0.45 and 0.64 (mean rho $=0.55$ ), and all p-values $<0.001$. For the variables used in the present study, the correlations varied from 0.46 to 0.53 .

In the current study, the data collection was administered by school nurses and headmasters. Most of the informants filled in the questionnaire themselves, but younger children and children who had problems with reading or writing were interviewed by the school nurses. Thus, 180 children in grades 1-4, 53 children in grades 5-7, and three children in grades 8-10 were interviewed by trained school nurses who used the questionnaire as a guide. Under the instruction of the school nurse or a trained teacher the remaining 183 children completed the questionnaires themselves during a lesson that was allocated to this task. At home, one parent filled in the parents' version of the questionnaire, and the class teacher filled in one questionnaire for each child. The questionnaires from different informants were connected by a specific code.

\section{Measures}

The questionnaires consisted of a combination of items that may promote wellbeing, and items that may adversely affect wellbeing. Victimization (being bullied) was one of the factors that could adversely be associated with good health. Responses to the questions were ranked on ordinal scales, and responses were to be relevant for the current school year. The following items were addressed, each with the corresponding questions:

\section{Victimization reported by the children}

Three questions were asked: "During recess, are you bothered in some way that makes you feel bad: 1) by being teased, 2) by being hit, kicked, or pushed, 3) by being left out, excluded?". Each question had five response options (1-5): never, seldom, sometimes, about every week, and about every day. In the analyses, we employed the question(s) with the highest response score of the three questions (the max score, i.e. one score only).

\section{Victimization reported by parents/teachers}

Two questions were asked: "During recess, do others tease or bother your daughter (son) / this child?", and "Does your daughter (son) / this child experience being left out from being together with peers?" Each question had five response options (1-5): never, seldom, sometimes, about every week, and about every day. In the analyses, we employed the question(s) with the highest response score of the two questions (the max score, i.e. one score only).

\section{Health symptoms reported by the children}

Four questions were asked: "Lately, how often have you felt: 1) sadness, 2) anxiety, 3) stomach ache, 4) headache?" Each question had five response options (1-5): never, seldom, sometimes, often, and always. Sadness and anxiety were denoted emotional symptoms, stomach ache and headache were denoted somatic symptoms.

\section{Ethics}

The survey was approved by the statutory School Collaborative Committees, and the collection of data was approved by The Norwegian Data Inspectorate. 


\section{Statistics}

Frequency of victimization as reported by the children, by the parents and by the teachers, was used as the "exposure" variable, and the four health symptoms were "outcome" variables. In the correlation analyses, all five options of victimization were used, whereas in the regression analyses, the last two categories were merged to weekly/daily because of low numbers. Each health symptom was dichotomized into "never/seldom" versus "sometimes/very often/all the time". We used logistic regression analysis to assess the association of victimization frequency with the odds of reporting health symptoms. In the analyses, we adjusted for children's gender and grade in school. Precision of the associations (odds ratios) were assessed using 95\% confidence intervals. Correlations were analyzed by Spearman's rho, and paired ordinal data were compared using the marginal homogeneity test. Tests for statistical significance were two-sided, and p-values $<0.05$ were considered significant. The statistical analyses were performed in SPSS for Windows (version 18 SPSS, Chicago, Illinois).

\section{Results}

The distribution of the exposure (victimization) and the outcomes (health symptoms) is shown in Table 1 . The three informant groups - children, teachers, and parents - reported nearly the same proportions of victimization, but overall, there was a tendency for children to report less victimization than that reported by teachers or parents $(\mathrm{p}=0.12$ and $\mathrm{p}=.042$, respectively), whereas the reporting of parents and teachers was similar $(p=0.39)$, marginal homogeneity test. The categories never and seldom victimized (options 1 and 2) were reported for about $80 \%$ of the children, sometimes (option 3 ) was reported for $14-20 \%$, and weekly and daily victimization (options 4 and 5) was reported for 2-4\%. Among the children, more than one of four reported to have

Table 1 The distribution of response options for health symptoms and victimization

\begin{tabular}{|c|c|c|c|c|c|c|c|c|}
\hline \multirow[t]{3}{*}{ Variables } & \multicolumn{5}{|c|}{ Response options ${ }^{a}$} & \multirow{3}{*}{$\begin{array}{c}\text { Total } \\
\mathrm{N}\end{array}$} & \multirow{3}{*}{ Mean } & \multirow{3}{*}{ SD } \\
\hline & 1 & 2 & 3 & 4 & 5 & & & \\
\hline & $\%$ & $\%$ & $\%$ & $\%$ & $\%$ & & & \\
\hline$\overline{\text { Victimization }^{b}}$ & 55.2 & 24.2 & 16.5 & 2.2 & 1.9 & 417 & 1.71 & 0.95 \\
\hline Victimization $^{c}$ & 40.5 & 43.5 & 13.7 & 1.0 & 1.2 & 402 & 1.79 & 0.81 \\
\hline Victimization $^{\mathrm{d}}$ & 41.1 & 36.0 & 19.5 & 1.9 & 1.6 & 375 & 1.87 & 0.90 \\
\hline Sadness ${ }^{b}$ & 24.5 & 48.9 & 23.5 & 2.7 & 0.5 & 413 & 2.06 & 0.79 \\
\hline Anxiety $^{b}$ & 54.7 & 28.0 & 12.9 & 3.2 & 1.2 & 411 & 1.68 & 0.90 \\
\hline Stomach ache ${ }^{b}$ & 39.6 & 31.9 & 21.7 & 5.1 & 1.7 & 414 & 1.97 & 0.99 \\
\hline Headache $^{\mathrm{b}}$ & 38.7 & 28.5 & 23.6 & 7.3 & 1.9 & 411 & 2.05 & 1.04 \\
\hline
\end{tabular}

${ }^{a}$ From 1 (never) to 5 (most frequently)

${ }^{\mathrm{b}}$ Reported by children

c Reported by teachers

${ }^{\mathrm{d}}$ Reported by parents experienced sadness, stomach ache, or headache sometimes, often, or always (options 3-5), and 17\% reported a similar frequency of anxiety.

Even though the reported proportions of victimization were fairly similar for the three groups of responders, the concordance in two-way cross-tables of children's responses with those of the respective teacher or parent varied from complete agreement to complete discordance (Table 2). We received responses from 397 childteacher pairs (Table 2a), from 371 child-parent pairs (Table 2b), and from 359 teacher-parent pairs (Table 2c). The variations in agreement may be exemplified by Table 2a; among 17 children who reported being victims of bullying weekly or daily, teachers reported 10 of these children as being victimized never or rarely, 4 were assigned sometimes, and for 3 children the agreement was complete. Children's reports of being victimized sometimes showed a corresponding concordance with the teachers' reports of victimization. On the other hand, children's reports of being never or seldom victimized (options 1 and 2) were confirmed by teachers in $274(88 \%)$ of the 312 cases and by parents (Table $2 \mathrm{~b}$ ) in 245 (84\%) of 292 cases. The estimated correlations (Spearman's rho) between responses were 0.17 for children and teachers, 0.29 for children and parents, and 0.36 for teachers and parents. All correlations were statistically significant (all p-values $\leq 0.001$ ).

Table 2 Three cross-tables $(2 a, 2 b, 2 c)$ of victimization (numbers) reported by different informants

\begin{tabular}{|c|c|c|c|c|}
\hline \multirow[t]{2}{*}{ 2a. Victimization reported by: } & \multicolumn{4}{|c|}{ Teachers } \\
\hline & 1 & 2 & 3 & 4 \\
\hline \multicolumn{5}{|l|}{ Children } \\
\hline 1: Never & 94 & 99 & 19 & 2 \\
\hline 2: Seldom & 43 & 38 & 15 & 2 \\
\hline 3: Sometimes & 22 & 28 & 16 & 2 \\
\hline 4: Weekly/daily & 3 & 7 & 4 & 3 \\
\hline \multirow[t]{2}{*}{ 2b. Victimization reported by: } & \multicolumn{4}{|c|}{ Parents } \\
\hline & 1 & 2 & 3 & 4 \\
\hline \multicolumn{5}{|l|}{ Children } \\
\hline 1: Never & 99 & 76 & 23 & 4 \\
\hline 2: Seldom & 35 & 35 & 18 & 2 \\
\hline 3: Sometimes & 17 & 18 & 25 & 3 \\
\hline 4: Weekly/daily & 1 & 4 & 7 & 4 \\
\hline \multirow[t]{2}{*}{ 2c. Victimization reported by: } & \multicolumn{4}{|c|}{ Parents } \\
\hline & 1 & 2 & 3 & 4 \\
\hline \multicolumn{5}{|l|}{ Teachers } \\
\hline 1: Never & 78 & 52 & 15 & 0 \\
\hline 2: Seldom & 59 & 64 & 33 & 2 \\
\hline 3: Sometimes & 8 & 13 & 20 & 9 \\
\hline 4: Weekly/daily & 0 & 1 & 4 & 1 \\
\hline
\end{tabular}


Table 3 Associations of children's self-reported peer victimization with their reports of health symptoms

\begin{tabular}{|c|c|c|c|c|c|c|c|c|}
\hline \multirow[b]{3}{*}{ Victimization reported by: } & \multicolumn{8}{|c|}{ Health symptoms reported by the children } \\
\hline & \multicolumn{2}{|c|}{ Sadness } & \multicolumn{2}{|c|}{ Anxiety } & \multicolumn{2}{|c|}{ Stomach ache } & \multicolumn{2}{|c|}{ Headache } \\
\hline & $\begin{array}{c}\text { Odds ratio } \\
(95 \% \mathrm{Cl})\end{array}$ & $S \& V^{a} / V^{e}$ & $\begin{array}{c}\text { Odds ratio } \\
(95 \% \mathrm{Cl})\end{array}$ & $A \& V^{b} / V^{e}$ & $\begin{array}{c}\text { Odds ratio } \\
(95 \% \mathrm{Cl})\end{array}$ & Sa\&V $/ V^{e}$ & $\begin{array}{l}\text { Odds ratio } \\
(95 \% \mathrm{Cl})\end{array}$ & $\mathrm{Ha \& V} / \mathrm{V}^{\mathrm{e}}$ \\
\hline Children & & $\mathbf{N}$ & & $\mathrm{N}$ & & $\mathrm{N}$ & & $\mathrm{N}$ \\
\hline Never & 1.00 & $53 / 227$ & 1.00 & $26 / 226$ & 1.00 & $51 / 229$ & 1.00 & $62 / 227$ \\
\hline Seldom & $1.0(0.5$ to 1.7$)$ & $23 / 99$ & $2.0(1.1$ to 3.9$)$ & 20/99 & $1.4(0.8$ to 2.4$)$ & 28/99 & $1.8(1.1$ to 3.1$)$ & $37 / 98$ \\
\hline Sometimes & 1.6 (0.9 to 3.0$)$ & $25 / 69$ & $3.5(1.7$ to 7.0$)$ & $19 / 68$ & $2.0(1.1$ to 3.6$)$ & $26 / 68$ & 1.9 (1.0 to 3.5$)$ & $24 / 68$ \\
\hline Weekly/daily & $\begin{array}{c}3.8(1.3 \text { to } \\
10.8)\end{array}$ & $9 / 16$ & $\begin{array}{c}5.3(1.7 \text { to } \\
16.1)\end{array}$ & $6 / 16$ & $\begin{array}{c}6.7 \text { (2.2 to } \\
20.4)\end{array}$ & $11 / 16$ & $\begin{array}{c}7.4(2.4 \text { to } \\
23.0)\end{array}$ & $11 / 16$ \\
\hline
\end{tabular}

Logistic regression with sadness, anxiety, stomach ache and headache as the dependent variables and victimization as categorical covariate adjusted for gender and grade. The prevalence is stated in numbers $(\mathrm{N})$.

a Sadness \& Victimization

${ }^{\mathrm{b}}$ Anxiety \& Victimization

' Stomach ache \& Victimization

${ }^{\mathrm{d}}$ Headache \& Victimization

e Victimization

We assessed the association of victimization with the prevalence of reported health symptoms, after adjustment for gender and grade. In Table 3, we present associations (odds ratios) of victimization with health symptoms as reported by the children: the results show that a gradual increase in victimization was associated with higher odds of reported health symptoms. Weekly or daily victimization was most strongly associated with both emotional and somatic health symptoms. Compared to never being victimized (the reference category), weekly/daily victimization was associated with approximately seven-fold higher odds of stomach ache (odds ratio, $6.7,95 \%$ CI 2.2 to 20.4 ) or headache (odds ratio, 7.4, $95 \%$ CI 2.4 to 23.0 ). In relation to emotional symptoms, the corresponding associations with sadness (odds ratio, 3.8, 95\% CI 1.3 to 10.8 ) and anxiety (odds ratio, $5.3,95 \%$ CI 1.7 to 16.1 ) were also very strong. Less frequent victimization (sometimes) showed statistically significant associations with anxiety, stomach ache and headache (Table 3), and the category seldom victimized was associated with higher odds of anxiety and headache compared to the reference category.

In separate analyses of boys and girls, the associations of victimization with health symptoms did not substantially differ between the genders, and by dividing the school grades in three groups $(1-4,5-7$, and 8-10), the results showed no substantial variation across groups of grades (results not shown).

Similar analyses as those reported in Table 3 were conducted using the frequency of victimization reported by the parents, and by the teachers. Table 4 shows that peer victimization reported by teachers was strongly associated with the children's reported anxiety, but there was no clear association for sadness, or for the somatic symptoms. For victimization reported by parents, each level of victimization was positively associated with

Table 4 Associations of teacher-reported peer victimization with health symptoms reported by the children

\begin{tabular}{|c|c|c|c|c|c|c|c|c|}
\hline \multirow[b]{3}{*}{ Victimization reported by: } & \multicolumn{8}{|c|}{ Health symptoms reported by the children } \\
\hline & \multicolumn{2}{|c|}{ Sadness } & \multicolumn{2}{|c|}{ Anxiety } & \multicolumn{2}{|c|}{ Stomach ache } & \multicolumn{2}{|c|}{ Headache } \\
\hline & $\begin{array}{c}\text { Odds ratio } \\
(95 \% \mathrm{Cl})\end{array}$ & $S \& V^{a} / V^{e}$ & $\begin{array}{c}\text { Odds ratio } \\
(95 \% \mathrm{Cl})\end{array}$ & $A \& V^{b} / V^{e}$ & $\begin{array}{l}\text { Odds ratio } \\
(95 \% \mathrm{Cl})\end{array}$ & Sa\&V ${ }^{c} V^{e}$ & $\begin{array}{c}\text { Odds ratio } \\
(95 \% \mathrm{Cl})\end{array}$ & $\mathrm{Ha} \& \mathrm{~V}^{\mathrm{d}} / \mathrm{V}^{\mathrm{e}}$ \\
\hline Teachers & & $\mathrm{N}$ & & $\mathrm{N}$ & & $\mathrm{N}$ & & $\mathbf{N}$ \\
\hline$\overline{\text { Never }}$ & 1.00 & $46 / 162$ & 1.00 & $20 / 162$ & 1.00 & $42 / 163$ & 1.00 & $45 / 162$ \\
\hline Seldom & 0.8 (0.5 to 1.3$)$ & $44 / 168$ & 1.5 (0.8 to 2.8$)$ & 28/166 & $1.1(0.7$ to 1.8$)$ & $51 / 169$ & 1.5 (0.9 to 2.4) & $57 / 168$ \\
\hline Sometimes & 0.9 (0.4 to 1.8$)$ & $14 / 55$ & $2.9(1.4$ to 6.1$)$ & $16 / 55$ & 1.5 (0.8 to 3.0$)$ & $19 / 54$ & $1.5(0.8$ to 3.0$)$ & $20 / 53$ \\
\hline Weekly/daily & $1.4(0.3$ to 6.2$)$ & $3 / 8$ & $4.3(1.0$ to 19.5$)$ & $3 / 8$ & 2.5 (0.6 to 10.6$)$ & $4 / 8$ & 1.6 (0.4 to 7.0$)$ & $3 / 8$ \\
\hline
\end{tabular}

Logistic regression with sadness, anxiety, stomach ache and headache as the dependent variables and victimization as categorical covariate adjusted for gender and grade. The prevalence is stated in numbers $(\mathrm{N})$.

a Sadness \& Victimization

b Anxiety \& Victimization

c Stomach ache \& Victimization

${ }^{d}$ Headache \& Victimization

e Victimization 
Table 5 Associations of parent-reported peer victimization with health symptoms reported by the children

\begin{tabular}{|c|c|c|c|c|c|c|c|c|}
\hline \multirow[b]{3}{*}{ Victimization reported by: } & \multicolumn{8}{|c|}{ Health symptoms reported by the children } \\
\hline & \multicolumn{2}{|c|}{ Sadness } & \multicolumn{2}{|c|}{ Anxiety } & \multicolumn{2}{|c|}{ Stomach ache } & \multicolumn{2}{|c|}{ Headache } \\
\hline & $\begin{array}{c}\text { Odds ratio } \\
(95 \% \mathrm{Cl})\end{array}$ & $S \& V^{a} / V^{e}$ & $\begin{array}{c}\text { Odds ratio } \\
(95 \% \mathrm{Cl})\end{array}$ & $A \& V^{b} / V^{e}$ & $\begin{array}{c}\text { Odds ratio } \\
(95 \% \mathrm{Cl})\end{array}$ & Sa\&V $/ V^{e}$ & $\begin{array}{c}\text { Odds ratio } \\
(95 \% \mathrm{Cl})\end{array}$ & $\mathrm{Ha} \& \mathrm{~V}^{\mathrm{d}} / \mathrm{V}^{\mathrm{e}}$ \\
\hline Parents & & $\mathrm{N}$ & & $\mathbf{N}$ & & $\mathbf{N}$ & & $\mathrm{N}$ \\
\hline Never & 1.00 & $37 / 152$ & 1.00 & $12 / 150$ & 1.00 & $36 / 152$ & 1.00 & $61 / 152$ \\
\hline Seldom & $1.1(0.6$ to 1.8$)$ & $37 / 133$ & $3.1(1.4$ to 6.7$)$ & $24 / 133$ & 1.5 (0.9 to 2.6$)$ & $45 / 134$ & $\begin{array}{l}0.6 \text { (0.4 to } \\
1.0)\end{array}$ & $34 / 133$ \\
\hline Sometimes & 1.1 (0.6 to 2.1$)$ & $21 / 73$ & $5.3(2.3$ to 12.2$)$ & $19 / 73$ & 1.2 (0.6 to 2.2 ) & $21 / 71$ & $\begin{array}{l}0.9 \text { ( } 0.5 \text { to } \\
1.7)\end{array}$ & $24 / 71$ \\
\hline Weekly/daily & $\begin{array}{l}3.3(1.0 \text { to } \\
10.5)\end{array}$ & $7 / 13$ & $\begin{array}{l}17.1(4.7 \text { to } \\
61.7)\end{array}$ & $7 / 13$ & $\begin{array}{l}5.0(1.5 \text { to } \\
16.7)\end{array}$ & $8 / 13$ & $\begin{array}{l}2.9 \text { (0.9 to } \\
9.5)\end{array}$ & $8 / 13$ \\
\hline
\end{tabular}

Logistic regression with sadness, anxiety, stomach ache and headache as the dependent variables and victimization as categorical covariate adjusted for gender and grade. The prevalence is stated in numbers $(\mathrm{N})$.

a Sadness \& Victimization

${ }^{\text {b }}$ Anxiety \& Victimization

c Stomach ache \& Victimization

${ }^{d}$ Headache \& Victimization

e Victimization

anxiety (Table 5), and the highest level of victimization was associated with sadness and stomach ache.

\section{Discussion}

In this cross-sectional study of school children, victimization caused by bullying was individually reported by the children, their teacher and their parents, and the concordance between informants was low to moderate. The associations of victimization, as reported by the three sources of information, with the prevalence of emotional and somatic complaints, as reported by the children were also compared. The children's own report of victimization was strongly associated with emotional and somatic complaints, but the reports by teachers and parents showed weaker associations and were mainly related to higher prevalence of anxiety.

The study was conducted in rural communities, ranging from inland to coastal areas. All children attended schools in the Norwegian public school system. The population base and the very high participation are strengths of the study; however, it is a weakness that the data do not include children from urban settings. The convenience sampling of schools and the fact that some schools had grades 1-7 whereas others had grades 1-10 may also be limitations. The reported prevalence of victimization and the consistency of information provided by different informants are, however, in line with findings from other studies. In the collection of data, the younger children were interviewed by school nurses, whereas older children completed the questionnaire themselves. Although the nurses were trained for this task, we cannot exclude the possibility that the different procedures could have influenced the participants and introduced systematic differences in results between younger and older children. The cross-sectional design is a limitation of this study, since cross-sectional designs limit the possibility to study causal effects; the findings must therefore be interpreted with caution.

Self-reports showed that one in five children perceived themselves as being victimized sometimes or more often, and this proportion does not differ substantially from previous findings of Norwegian school children $[16,25,26]$. Moreover, the prevalence of victimization, as reported by children, teachers, and parents, was fairly similar, although there was a tendency for children to report a lesser degree of victimization. Others have reported differences between informants, where children generally report a higher prevalence of victimization than teachers or parents $[27,28]$.

Only a few studies have assessed the concordance between children's self-reports of victimization and teachers' reports. Of these, Nuijens et al. [29] found no concordance, while other results $[19,30]$ are fairly similar to ours. The agreement - discordance between selfreports and parental reports has rarely been assessed [19], but in a recent such study [31], the estimated consistency for children who reported to be victimized was higher than in our study, but lower for children who perceived themselves not to be victimized. However, only a small proportion of parents (28\%) provided information in that study, and the results may be less reliable than our findings.

In line with previous findings $[1,6,8]$, victimization as reported by the children showed strong associations with self-reports of emotional and somatic symptoms. To our awareness, no previous studies have assessed the association of victimization reported by parents with health complaints reported by the children. We found, 
however, weaker associations of parental reports of victimization with children's self-reported health symptoms compared to children's reports of victimization associated with health symptoms. Victimization as reported by teachers also showed weaker associations with children's health symptoms, and this finding corresponds with results from a recent study [29]. It has been suggested [8] that if exposures and outcomes are simultaneously reported (shared variance), this may result in stronger associations than if the information is derived from different sources. To some degree, this may explain some of the differences in the estimated associations of our study, but the findings call for attention nonetheless.

Further, our results suggest that the frequency of victimization may be particularly important since frequency was positively associated with the prevalence of health symptoms, as reported by the children. In studies where victimization was dichotomized, weak associations have been reported [32], whereas in studies using graded categories of victimization, the associations with health symptoms have typically been stronger among children who report relatively higher frequency of victimization [33]. The effect of dose has also been suggested in a large international study [3]. For all the 28 countries that were included, the symptom load increased with increasing frequency of victimization.

Generally, researchers differ in how they regard the low agreement between respondents [22]. In relation to research on wellbeing and quality of life, comprehensive information from different sources may yield important nuances that may enrich the understanding of children's adjustments $[20,21]$. In relation to psychopathology, some may prefer to handle information from different sources separately [23,34], whereas others suggest deriving consensus by using information from different perspectives and settings [35,36]. In relation to peer victimization, our results suggest that differences between the sources of information should not be ignored. Children who experience being victimized may be overlooked by significant adults, and these children may at the same time experience high burdens of emotional and somatic symptoms.

\section{Conclusions}

Victims of bullying in school reported high prevalence of sadness, anxiety, stomach ache and headache, and the association with health symptoms showed a strong and graded relation to the frequency of victimization. Children, teachers, and parents reported fairly similar proportions of children to be victimized, but the concordance between informants varied from complete agreement to complete discordance for victimization reported at the highest frequency (weekly/daily).
Compared to children's reports, victimization as reported by teachers or parents showed weaker associations with children's self-reported health symptoms. Agreement - discordance among informants should be further assessed, and longitudinal studies may clarify the importance of collecting information on peer victimization from different sources.

\section{Acknowledgements}

We wish to thank the school nurses, school headmasters, teachers and parents who contributed, and a special thanks to the children. The study was financially supported by the National Education Office, Møre and Romsdal County, and by the Central Norway Regional Health Authority.

\section{Author details}

'Department of Public Health, Faculty of Medicine, Norwegian University of Science and Technology, Trondheim, Norway. ${ }^{2}$ The Central Norway Regional Health Authority, Stiørdal, Norway. ${ }^{3}$ Unit for Applied Clinical Research, Department of Cancer Research and Molecular Medicine, Faculty of Medicine, Norwegian University of Science and Technology, Trondheim, Norway. ${ }^{4}$ Sintef Health Center Research, Trondheim, Norway. ${ }^{5}$ Center for Child and Adolescent Mental Health, University of Bergen, Norway. ${ }^{6}$ Sogn og Fjordane University College, Sogndal, Norway.

\section{Authors' contributions}

The present cross-sectional study is part of a two year follow-up, planned and administered by AL. All authors participated in designing the study. AL and SL did the analyses. All authors interpreted the data and wrote the paper, and all authors have read and approved the final manuscript.

\section{Competing interests}

The authors declare that they have no competing interests.

Received: 10 October 2010 Accepted: 6 May 2011

Published: 6 May 2011

\section{References}

1. Arseneault $L$, Bowes $L$, Shakoor S: Bullying victimization in youths and mental health problems: Much ado about nothing? Psychol Med 2010, 40(05):717-729.

2. Bond L, Carlin JB, Thomas $L$, Rubin $K$, Patton G: Does bullying cause emotional problems? A prospective study of young teenagers. BMJ 2001, 323(7311):480-484

3. Due P, Holstein BE, Lynch J, Diderichsen F, Gabhain SN, Scheidt P, Currie C: Bullying and symptoms among school-aged children: International comparative cross sectional study in 28 countries. Eur J Public Health 2005, 15(2):128-132.

4. Fekkes M, Pijpers FI, Verloove-Vanhorick SP: Bullying behavior and associations with psychosomatic complaints and depression in victims. J Pediatr 2004, 144(1):17-22.

5. Gini G: Associations between bullying behaviour, psychosomatic complaints, emotional and behavioural problems. J Paediatr Child Health 2008, 44(9):492-497.

6. Gini G, Pozzoli T: Association between bullying and psychosomatic problems: A meta-analysis. Pediatrics 2009, 123(3):1059-1065

7. Graham S, Bellmore AD: Peer victimization and mental health during early adolescence. Theor Pract 2007, 46(2):138-146.

8. Hawker DSJ, Boulton MJ: Twenty years' research on peer victimization and psychosocial maladjustment: A meta-analytic review of crosssectional studies. J Child Psychol Psychiatry 2000, 41(4):441-455.

9. Lamb J, Pepler DJ, Craig WM: Approach to bullying and victimization. Can Fam Physician 2009, 55(4):356-360.

10. Nansel TR, Craig W, Overpeck MD, Saluja G, Ruan WJ: Cross-national consistency in the relationship between bullying behaviors and psychosocial adjustment. Arch Pediatr Adolesc Med 2004, 158(8):730-736.

11. Nansel TR, Overpeck M, Pilla RS, Ruan WJ, Simons-Morton B, Scheidt P. Bullying behaviors among US youth: Prevalence and association with psychosocial adjustment. JAMA 2001, 285(16):2094-2100. 
12. Rigby K: Peer victimisation at school and the health of secondary school students. Br J Educ Psychol 1999, 69(1):95-104.

13. Wolke D, Woods S, Bloomfield L, Karstadt L: Bullying involvement in primary school and common health problems. Arch Dis Child 2001, 85(3):197-201.

14. Williams K, Chambers M, Logan S, Robinson D: Association of common health symptoms with bullying in primary school children. BMJ 1996, 313(7048):17-19

15. Rosen L, Underwood M, Beron K, Gentsch J, Wharton M, Rahdar A: Persistent versus periodic experiences of social victimization: Predictors of adjustment. J Abnorm Child Psychol 2009, 37(5):693-704.

16. Olweus D: Bullying at school. What we know and what we can do. Oxford, U.K.: Blackwell; 1993.

17. Smith PK, Brain P: Bullying in schools: Lessons from two decades of research. Aggress Behav 2000, 26(1):1-9.

18. Smith PK: Bullying: Recent Developments. Child Adolesc Ment Health 2004, 9(3):98-103.

19. Ladd GW, Kochenderfer-Ladd B: Identifying victims of peer aggression from early to middle childhood: analysis of cross-informant data for concordance, estimation of relational adjustment, prevalence of victimization, and characteristics of identified victims. Psychol Assess 2002, 14(1):74-96.

20. Achenbach TM, McConaughy SH, Howell CT: Child/adolescent behavioral and emotional problems: Implications of cross-informant correlations for situational specificity. Psychol Bull 1987, 101(2):213-232.

21. Jozefiak T, Larsson B, Wichstrom L, Mattejat F, Ravens-Sieberer U: Quality of Life as reported by school children and their parents: a cross-sectional survey. Health Qual Life Outcomes 2008, 6(1):34.

22. De Los Reyes A, Kazdin AE: Informant discrepancies in the assessment of childhood psychopathology: A critical review, theoretical framework, and recommendations for further study. Psychol Bull 2005, 131(4):483-509.

23. Munkvold L, Lundervold A, Lie SA, Manger T: Should there be separate parent and teacher-based categories of ODD? Evidence from a general population. J Child Psychol Psychiatry 2009, 50(10):1264-1272.

24. Løhre A, Lydersen S, Vatten L: School wellbeing among children in grades 1-10. BMC Public Health 2010, 10:526.

25. Roland E: Bullying in school: Three national innovations in Norwegian schools in 15 years. Aggress Behav 2000, 26(1):135-143.

26. Solberg ME, Olweus D: Prevalence estimation of school bullying with the Olweus Bully/Victim Questionnaire. Aggress Behav 2003, 29(3):239-268.

27. Bradshaw CP, Sawyer AL, O'Brennan LM: Bullying and peer victimization at school: Perceptual differences between students and school staff. School Psych Rev 2007, 36(3):361-382.

28. Stockdale MS, Hangaduambo S, Duys D, Larson K, Sarvela PD: Rural elementary students', parents', and teachers' perceptions of bullying. Am J Health Behav 2002, 26(4):266-277.

29. Nuijens KL, Teglasi H, Hancock GR: Self-perceptions, discrepancies between self- and other-perceptions, and children's self-reported emotions. J Psychoeduc Assess 2009, 27(6):477-493.

30. Cornell DG, Brockenbrough K: Identification of bullies and victims: A comparison of methods. J Sch Violence 2004, 3(2):63-87.

31. Holt MK, Kaufman Kantor G, Finkelhor D: Parent/child concordance about bullying involvement and family characteristics related to bullying and peer victimization. J Sch Violence 2009, 8(1):42-63.

32. Forero R, McLellan L, Rissel C, Bauman A: Bullying behaviour and psychosocial health among school students in New South Wales, Australia: Cross sectional survey. BMJ 1999, 319(7206):344-348.

33. Natvig GK, Albrektsen G, Qvarnstrom U: Psychosomatic symptoms among victims of school bullying. J Health Psychol 2001, 6(4):365-377.

34. Offord DR, Boyle MH, Racine Y, Szatmari P, Fleming JE, Sanford M, Lipman EL: Integrating assessment data from multiple informants. J Am Acad Child Adolesc Psychiatry 1996, 35(8):1078-1085.

35. Kraemer HC, Measelle JR, Ablow JC, Essex MJ, Boyce WT, Kupfer DJ: A new approach to integrating data from multiple informants in psychiatric assessment and research: Mixing and matching contexts and perspectives. Am J Psychiatry 2003, 160(9):1566-1577.

36. Perren S, von Wyl A, Stadelmann S, Bürgin D, von Klitzing K: Associations between behavioral/emotional difficulties in kindergarten children and the quality of their peer relationships. J Am Acad Child Adolesc Psychiatry 2006, 45(7):867-876.

\section{Pre-publication history}

The pre-publication history for this paper can be accessed here: http://www.biomedcentral.com/1471-2458/11/278/prepub

doi:10.1186/1471-2458-11-278

Cite this article as: Løhre et al:: Peer victimization as reported by children, teachers, and parents in relation to children's health symptoms. BMC Public Health 2011 11:278.

\section{Submit your next manuscript to BioMed Central and take full advantage of:}

- Convenient online submission

- Thorough peer review

- No space constraints or color figure charges

- Immediate publication on acceptance

- Inclusion in PubMed, CAS, Scopus and Google Scholar

- Research which is freely available for redistribution

Submit your manuscript at www.biomedcentral.com/submit
Biomed Central 